\title{
Chemical colitis caused by hydrogen peroxide enema in a child: case report and literature review
}

\author{
Joon Sang Lee, Jung Kyung Yoo \\ Department of Pediatrics, National Police Hospital, Seoul, Korea
}

Notice of Retraction: Lee JS et al. Chemical colitis caused by hydrogen peroxide enema in a child: case report and literature review. Environ Health Toxicol 2017;32:e2017002.

The following article from Environmental Health and Toxicology (EHT), "Chemical colitis caused by hydrogen peroxide enema in a child: case report and literature review," published on December 29, 2016 has been retracted from publication.

The authors violated the publication ethics by their dual submission and publication to our journal and the J Korean Soc Emerg Med 2017;28(2):223-226: "Chemical colitis caused by hydrogen peroxide enema in a child: a case report and literature review". The contents were the same in papers published in both the journals. And the authors had agreed to and confirmed the "Submission Agreement"; therefore, the authors are considered to have violated EHT's policy on duplicate submissions.

Therefore, the editorial board of the EHT decided to retract this paper from our journal. We apologize to readers and try the best to thoroughly screen any plagiarisms and ethics violations prior to the publications of papers submitted and accepted in our journal. 